\title{
Da Administração Científica às Ciências da Administração
}

\author{
Benedicto Silva \\ Técnico de Administração; diretor do Instituto \\ de Documentação da Fundação Getúlio Vargas \\ (INDOC)
}

Nos tempos atuais, o conhecimento envelhece quase tão rapidamente quanto a moda. Por exemplo: há vinte anos passados, o corpo de conhecimentos teóricos utilizados na formação do administrador tinha por núcleo central o taylorismo, isto é, aquilo que, na literatura pertinente, veio a chamar-se scientific management.

Havendo perfeita complementariedade entre a doutrina de Fayol e o sistema de Taylor, o fayolismo fazia parte integrante do scientific management, pelo menos no Brasil.

Conseqüentemente, era inconcebível não considerar o taylorismo e o fayolismo como disciplinas essenciais do ensino da administração.

Hoje, o cenário das disciplinas reunidas sob o rótulo management sciences é tão diverso do cenário do scientific management, tão mais amplo, que chega a causar espanto ao observador.

Naquela época, a abordagem interdisciplinar dos curricula de ensino estava apenas raiando no Brasil, ao passo que hoje já se fala até na abordagem unificada.

Durante a II Guerra Mundial surgiu uma tendência para a aplicação da ciência ao estudo e solução dos problemas administrativos das forças beligerantes e das empresas industriais. Graças aos resultados obtidos, essa tendência, já então trans- 
formada em interesse militante, cresceu e consolidou-se no após-guerra. Informa C. West Churchmann que isso provocou o surgimento de entidades novas e novedosas, em vários países, como a Sociedade de Pesquisa Operacional (Inglaterra), as Sociedades de Pesquisa de Operações (Estados Unidos), a Société Française de Recherche Operationalle. A expressão inglesa operations research, que figura na denominação de algumas dessas entidades, foi originariamente usada pelas forças armadas da Inglaterra e dos Estados Unidos para designar a tarefa dos grupos de cientistas que analisavam as operações militares. Logo, porém, passou a designar genericamente a aplicação da ciência a quaisquer operações desencadeadas e controladas por administradores. Daí serem às vezes empregadas como sinônimos as expressões management science e operation research. 1

Estendendo-se ao processo decisório, à teoria da decisão e à teoria da organização, isto é, aos três domínios placentários do managerial process, era esperável que esses cruzamentos semânticos dessem origem à expressão plural management sciences, que se adotou em língua inglesa (e já é verbete da Enciclopaedia Britannica, edição de 1967) para representar o interesse comum a diversas disciplinas científicas pelo estudo e solução de problemas administrativos.

O interesse intelectual comum não é o único fator de relacionamento entre as management sciences: ao preconizarem a necessidade de análises mais rigorosas dos complicados problemas administrativos, elas partilham também uma filosofia comum de métodos.

Tal necessidade é susceptível de ser atendida mediante a aplicação da matemática, ou às vezes mediante a observação e a experiência rigorsamente controladas. Nos dois casos, o procedimento deve aplicar-se sob a égide do espírito científico, expressão aqui empregada na acepção de Emile Boutroux: "O espirito científico é essencialmente o sentido do fato como fonte, regra, medida e comprovação de todo conhecimento". ${ }^{2}$

As management sciences são um feixe de mais de duas dezenas de disciplinas aparentemente heterogêneas, algumas Dividem-se em três categorias:

1. disciplinas clássicas: Ciência Política, Direito, História, Economia, Biologia, Lógica, Educação, Matemática; 
2. disciplinas modernas: Engenharia, Antropologia, Planejamento Urbano, Teoria da Organização, Administração Empresarial, Estatística Matemática, Contabilidade de Custos, e

3. disciplinas moderníssimas: Informática, Teoria da Fila, Teoria dos Jogos, Teoria da Decisão, Teoria do Inventário, Cibernética, Programação Linear, Programação Dinâmica, Automação.

Cabe observar que as management sciences estão sendo combinadas e cultivadas para habilitar o administrador a enfrentar os problemas das grandes organizações. A gerência das empresas de porte médio, e a fortiori a das pequenas empresas não reclama o concurso sofisticado de toda a bateria das management sciences.

É claro que a sua aplicação tende a afetar tanto o estado maior como o pessoal de linha e, em certos casos, pode incluir também pelo menos algum aspecto das atividades de qualquer membro da organização. A comunidade dos cientistas da administração tende a reconhecer, entretanto, que as atividades administrativas mais complexas, aquelas cujo desempenho desafia os titulares das management sciences, são as que recaem sobre os dirigentes e seus assessores mais graduados. Desdobram-se elas nos quatro grupos seguintes:

1. descoberta (ou identificação), desenvolvimento, definição e avaliação dos objetivos da organização e das políticas alternativas que propiciem a consecução desses objetivos;

2. adoção das políticas e dos planos pela organização;

3. verificação oportuna (concomitante ou a posteriori) da eficácia das políticas e dos planos adotados;

4. tomada de medidas para mudar as políticas e rever os planos quando aquelas e estes forem julgados menos eficazes do que deviam. ${ }^{3}$

As atividades constantes do item 1 freqüentemente se confundem com o planejamento. Trata-se de atividades "essencialmente cognitivas", desempenhadas por indivíduos ou grupos que utilizam informações e dados para eles coligidos por seus ajudantes (pesquisadores, assessores etc.). Os planos daí resul- 
tantes geralmente se dividem em planos de curto prazo e planos de longo prazo. Os dados de informações necessários à sua elaboração variam grandemente. A necessidade de cuidar da sobrevivência e do progresso permanente da organização impõe aos dirigentes os planos de longo alcance, que podem cobrir vários anos vindouros. Neste caso o planejador terá que levar em consideração muitos "objetivos sociais intangíveis", geralmente de somenos importância no planejamento a curto prazo.

A atividade constante do item 2 , a adoção das políticas e dos planos, representa uma das tarefas cruciais das grandes organizações. Ninguém consegue implementar um plano por meio de simples expedição de ordens orais e/ou escritas. Mobilizar grupos numerosos de pessoas e fazê-las mover coordenadamente "no rumo planejado pressupõe a existência de complicados sistemas de comunicação", enredando todos os níveis da hierarquia. Tato, paciência, sutileza, capacidade de persuasão e de motivação, tudo isso deve ser judiciosamente introduzido no processo administrativo.

A atividade constante do item 3 , a verificação oportuna da eficácia das políticas e dos planos adotados é freqüentemente chamada controle e, naquilo que implica quantificação, pode ficar a cargo de estatísticos e contadores.

A atividade constante do item 4 , o processo de mudar as políticas e os planos quando revelam sintomas de ineficácia, não somente requer um sistema integrado de informações, mas também pressupõe a escolha de meios que fiquem equidistantes da fúria das mudanças demasiado freqüentes e da lentidão das
mudanças demasiado raras. ${ }^{4}$

Percebe-se que o sistema Taylor, sozinho, apesar de sua riqueza e elasticidade operacional, já não equipa grupos de pessoas para desempenharem com eficiência, no seio das grandes empresas, as operações administrativas que acabamos de descrever sucintamente, baseando-nos em grande parte, aqui e ali quase literalmente, no verbete sobre management sciences que C. W. Churchmann escreveu para a edição de 1967 da Enciclopédia Britânica. ${ }^{5}$ É evidente que a problemática administrativa cursos intelectuais bem mais diversificado e muito mais inclusivo do que o oferecido pelo sistema Taylor. Mas requer, sobretudo, aquilo que o scientific management não pode oferecer: plena R. Serv. públ., Brasilia, 108 (3) set./dez. 1973 
atualização com o desenvolvimento científico e tecnológico do século XX.

Não há negar que o taylorismo e o fayolismo permanecem como estágios fundamentais do movimento chamado scientific management, que tantos serviços prestou à humanidade. Mas, como se vê, o advento das disciplinas moderníssimas acima enumeradas veio revolucionar de fond en comble todo o repertório de recursos intelectuais com que deve contar o executivo moderno.

O conceito de eficiência, por exemplo, base do scientific management, foi completamente alterado pelo emprego do computador nas atividades administrativas.

Por eficiência se entendia a obtenção do máximo de resultados com o mínimo de recursos materiais e temporais. A norma de trabalho preferida era a que determinasse menor emprego de tempo, de material, de espaço etc., para a obtenção de determinado volume de resultados. A economia de tempo era uma consideração essencial da eficiência.

Tratando-se, porém, de operações em que seja empregado o computador, qualquer preocupação com a economia de tempo perde a razão de ser. O computador funciona com incrível rapidez: pode consultar instantaneamente milhares e milhares de itens de informação registrados em sua memória e identificar 0 item buscado.

A atividade de planejamento, por sua vez, coluna mestra do taylorismo, sofreu tremendo impacto com a utilização da informática. Ainda não raiou a hora em que a atividade do administrador terá por base a informação recebida em regime de real time, mas os futurólogos já prevêem a era tecnotrônica. Então, a nau do Estado poderá ser conduzida como um automóvel: o motorista faz as manobras convenientes e instantâneas ao longo da estrada, de acordo com as circunstâncias cambiantes e percebidas en la marcha.

É certo, porém, que sem a informática muitas das proezas administrativas contemporâneas, - as viagens à lua, os longos vôos dos laboratórios espaciais e as transmissões intercontinentais de imagens e sons por intermédio de satélites colocados em órbita pelo homem - não poderiam ser planejadas, menos ainda executadas. Quer isso dizer que o processamento eletrônico da informação veio enriquecer colossalmente a instrumentalidade operacional do administrador. 
Comparado com o movimento das managements sciences, o movimento taylorista do scientific management apresenta diversas diferenças. Em suas primeiras fases, o taylorismo revelou-se principalmente interessado no controle das operações realizadas no interior das fábricas; omitiu-se no desenvolvimento de modelos matemáticos para esses procedimentos; valeu-se principalmente da observação cuidadosa e da mensuração física como método de descobrir e prescrever melhoramentos na execução das operações.

Diz Churchmann: "Talvez se possa precisar essa discrepância dizendo que o scientific management não se interessava em desenvolver um modelo que pudesse revelar todas as alternativas e indicar um critério para a otimização das opções. Aqueles que perfilham o scientific management - os engenheiros dos "sistemas e procedimentos" e do "tempo e movimento", por exemplo - se têm mantido de certo modo fora da comunidade das management sciences, segregação que pode muito bem vir a ser a fase de amadurecimento dos dois grupos". ${ }^{6}$

Há outra circunstância que indica a diferença quase abismal existente entre o volume de conhecimentos chamados scientific management e o das management sciences: um cérebro bem dotado pode assimilar profundamente todo o conjunto de ensinamento do taylorismo e do fayolismo. Mas a lista de disciplinas citadas anteriormente evidencia que, se fosse necessário conhecê-las e dominá-las todas para se chegar a ser um administrador profissional, a duração da vida não bastaria para aprendizado tão longo.

Esse fato torna claro que a tarefa de administrar nos tempos atuais transcende de muito a capacidade de qualquer indivíduo isolado. $\mathrm{O}$ administrador tipo estrela solitária tende a ser substituído por uma constelação de competências diferenciadas, isto é, um grupo humano em que estes complementam o saber e a experiência daqueles.

O aparecimento de superempresas nacionais e multinacionais também é uma conseqüência do advento das disciplinas administrativas moderníssimas. Estão se formando atualmente, na maioria das vezes por fusão, entidades empresariais de envergadura tão vasta, que sem a ajuda da informática - contandose apenas com os recursos do sistema Taylor - seria impos-
sível administrar. 
O processo decisório - é ou não é a prova de fogo do administrador? A estabilidade, o progresso, a própria sobrevivência das empresas - dependem ou não dependem diretamente das decisões de seus dirigentes? Quem se abalançará a responder negativamente a estas questões?

Os sinais da boa administração, da administração correta, sã, eficiente, o administrador manifesta-os, primeiro, no cuidado com que se informa antes de decidir; em seguida, na segurança com que analisa as informações pertinentes e distingue as decisões mais apropriadas, e, por fim, no fato de acertar em cheio na hora de tomá-las.

A administração não é exclusivamente um procedimento científico - é também uma criação artística. É admissível, assim, que pelo menos nas empresas médias e nas pequenas o processo decisório possa desenvolver-se eficazmente, sem que seja necessário ao dirigente empregar toda a bateria das ciências da administração.

Eis por que o repertório de idéias e práticas tayloristas e fayolistas conserva a sua validade. A administração computarizada pede grau de sofisticação muito além da capacidade da maioria dos administradores atuais.

Conjugado ao fayolismo, tayolorismo continuará ainda por muito tempo a ter aplicação e a produzir bons efeitos na empresa média e na empresa pequena.

Mesmo em determinados setores das grandes empresas, pode acontecer que o volume de trabalho não justifique nem a intervenção dispendiosa do computador, nem o recurso à complicada instrumentalidade das ciências da administração.

\section{REFERENCIAS}

1. CHURCHMANN, C. West. Management Sciences. Verbete in Encyclopaedia Britannica. Encyclopaedia Britannica, Inc. Chicago, 1967.

2. LAFONTAINE, A. P. Boutroux - Editorial Sudamericana - Buenos Aires, 1943 , p. 127.

3. CHURCHMANN, C. West. Op. cit. loc. cit.

6.

Op. cit. Ioc. cit.

Op. cit.

Op. cit. loc. cit. 
